\title{
VOLATILIZAÇÃO DE AMÔNIA PROVENIENTE DE UREIA COMPACTADA COM ENXOFRE E BENTONITA, EM AMBIENTE CONTROLADO $^{(1)}$
}

\author{
José Antônio de Oliveira ${ }^{(2)}$, Juliano Bahiense Stafanato ${ }^{(3)}$, Rosimar de Souza Goulart ${ }^{(2)}$, \\ Everaldo Zonta $^{(4)}$, Eduardo Lima ${ }^{(4)}$, Nelson Mazur ${ }^{(4)}$, Carlos Guerra Pereira ${ }^{(5)}$, Heraldo \\ Namorato de Souza ${ }^{(5)}$ \& Fábio Gerl Martins Costa ${ }^{(5)}$
}

\section{RESUMO}

Nos últimos anos, novas tecnologias têm sido desenvolvidas para reduzir as perdas de $\mathrm{N}$ quando se utiliza ureia como fonte desse macronutriente. A utilização de fertilizantes de características ácidas pode reduzir as perdas de amônia por volatilização, quando combinados com a ureia. $\mathrm{O}$ objetivo deste trabalho foi avaliar as perdas de amônia provenientes de fontes de $\mathrm{N}$ revestidas e, ou, incorporadas com ou sem enxofre e bentonita. Esses foram aplicados na superficie de um Planossolo Háplico contido em bandejas $\left(0,1 \mathrm{~m}^{2}\right.$ de área e $10 \mathrm{~cm}$ de profundidade), em dose equivalente a $200 \mathrm{~kg} \mathrm{ha}^{-1}$ de N. Foram avaliadas as perdas de $\mathrm{N}^{-\mathrm{NH}_{3}}$ por volatilização durante 21 dias, com auxílio de um coletor semiaberto. A adição de diferentes fontes de enxofre $\mathrm{e}$ de bentonita no processo de compactação da ureia reduziu as perdas de amônia em até $29 \%$, quando comparadas com a ureia granulada comercial, comprovando serem alternativas promissoras para aumentar a eficiência da adubação nitrogenada.

Termos para indexação: perdas de nitrogênio, fertilizantes compactados, NBPT.

\section{SUMMARY: VOLATILIZATIONOF AMMONIA FROM UREA COMPACTED WITH SULFUR AND BENTONITE IN A CONTROLLED ENVIRONMENT}

In recent years, new technologies have been developed to reduce $N$ losses when using urea as a source of this macronutrient. The use of fertilizers with acidic features can reduce ammonia losses from volatilization when combined with urea. The objective of this study was to assess

(1) Parte da Dissertação de Mestrado do primeiro autor. Recebido para publicação em 14 de outubro de 2013 e aprovado em 25 de junho de 2014.

(2) Mestre em Agronomia, Ciência do Solo, Departamento de Solos, Universidade Federal Rural do Rio de Janeiro - UFRRJ. BR 465, km 7. CEP 23851-970 Seropédica (RJ). E-mail: jaoliveirarural@yahoo.com.br, rs.goulart@hotmail.com

(3) Doutor em Agronomia, Ciência do Solo, Departamento de Solos, UFRRJ. E-mail: jstafanato@yahoo.com.br

(4) Professor Adjunto, Departamento de Solos, UFRRJ. E-mail: ezonta@ufrrj.br (Bolsista de Produtividade do CNPq), edulima@ufrrj.br, nelmazur@ufrrj.br

(5) Pesquisador da Petrobras/Cenpes/PDEDS/GEGQ. Av. Jequitibá, 950, Radial 6, sala 670, Ilha do Fundão. CEP 21941-598 Rio de Janeiro (RJ). E-mail: cgp.gorceix@petrobras.com.br, heraldo.ns@petrobras.com.br, fabcos@petrobras.com.br 


\begin{abstract}
ammonia losses from sources of $N$ with or without coating and/or incorporation of $S$ and bentonite. These fertilizers were applied to the surface of a Haplic Planosol contained in trays $\left(0.1 \mathrm{~m}^{2}\right.$ area and $10 \mathrm{~cm}$ deep) at an $\mathrm{N}$ rate of $200 \mathrm{~kg} \mathrm{ha}^{-1}$. Losses of $\mathrm{NH}_{3}$ through volatilization were evaluated for 21 days with the aid of a semi-open collector. The addition of different sources of $S$ and bentonite in the urea compaction process reduced ammonia loss by up to $29 \%$ when compared with commercial granulated urea, proving to be promising alternatives for increasing the efficiency of $N$ fertilization.
\end{abstract}

Index terms: nitrogen loss, compacted fertilizers, NBPT.

\section{INTRODUÇÃO}

No Brasil, a ureia representa mais da metade da matriz de adubos nitrogenados (Facre, 2007); desses mais de $70 \%$ são importados, demonstrando com isso a real necessidade de maiores investimentos no setor de desenvolvimento de novos produtos. Dentre as vantagens no uso da ureia em relação às demais fontes nitrogenadas, destaca-se principalmente a alta concentração de N (44 a $46 \%$ ), resultando consequentemente em menor custo no transporte e na aplicação (Kiehl, 1989). Esse fertilizante apresenta, no entanto, limitações quanto às perdas de $\mathrm{N}$, que podem comprometer a sua eficiência. A principal forma de perda de $\mathrm{N}$ ocorre pela hidrólise da ureia, resultando na formação de amônia e sua eventual volatilização (Rodrigues \& Kiehl, 1992). Esse processo é altamente influenciado pelas práticas de manejo e pelas características do solo, associadas às condições climáticas (Da Ros et al., 2005). As perdas ocorrem porque a ureia é hidrolisada rapidamente (dois a três dias) por meio da ação da enzima urease, que é produzida por microrganismos do solo e por restos de vegetais e animais (Reynolds \& Wolf, 1987).

Novas tecnologias adotadas com o intuito de minorar as perdas de amônia por volatilização têm sido desenvolvidas nos últimos anos. A principal delas é o uso de ureia em conjunto com inibidores da urease (principalmente NBPT) e a incorporação e, ou, revestimento da ureia com micronutrientes. Stafanato et al. (2013), avaliando a eficiência da ureia pastilhada com $\mathrm{Cu}$ e B, verificaram que esses micronutrientes reduziram as perdas de $\mathrm{N}-\mathrm{NH}_{3}$ por volatilização em aproximadamente $54 \%$, quando comparadas com as perdas ocasionadas pela ureia comercial.

Também, há tecnologias que consistem no uso de ureia recoberta com polímeros que interferem na hidrólise e, ou, solubilização da ureia no solo e na mistura de ureia com fertilizantes de características ácidas. Entre os fertilizantes nitrogenados mais utilizados, o sulfato de amônio é a fonte de $\mathrm{N}$ com caráter mais acidificante, além de não sofrer volatilização de $\mathrm{N}^{-\mathrm{NH}_{3}}$ quando o $\mathrm{pH}$ do solo encontrase abaixo de 7,0. Essa mistura (ureia + sulfato de amônio), quando aplicada ao solo, pode acarretar no aumento da concentração de íons $\mathrm{H}^{+}$próximo aos grânulos do fertilizante, minimizando os efeitos das perdas de amônia por volatilização. Vitti et al. (2002), avaliando a mistura de ureia com sulfato de amônio, verificaram redução nas perdas de amônia sem interferir na qualidade da mistura em relação aos atributos físico-químicos. Já em uma mistura de ureia e sulfato de amônio, no mesmo grânulo, nas proporções de 59,6 e 40,4 \%, respectivamente, Lara Cabezas et al. (1992) observaram menores perdas de amônia se comparada com ureia de diferentes granulometrias. As perdas menores de $\mathrm{NH}_{3}$ da ureia ocorreram em virtude, provavelmente, da reação acidificante do sulfato de amônio, próximo do grânulo, que pode neutralizar o efeito local de elevação do $\mathrm{pH}$ provocado pela hidrólise da ureia.

A forma da ureia pode também induzir à menor taxa de liberação do nutriente e, consequentemente, diminuir as suas perdas, seja por volatilização e, ou, lixiviação, ocasionando assim maior aproveitamento do N pelas plantas. Khalil et al. (2006) verificaram menores perdas de $\mathrm{N}$ por volatilização à medida que houve aumento no tamanho dos grânulos desse fertilizante. Entretanto, pesquisas evidenciaram também elevação na volatilização de $\mathrm{N}$ com o aumento de tamanho dos grânulos (Lara Cabezas et al., 1992).

Este trabalho foi realizado com o objetivo de avaliar o efeito da ureia incorporada ou não com enxofre e bentonita, na volatilização de amônia em um Planossolo Háplico em ambiente controlado.

\section{MATERIAL E MÉTODOS}

O experimento foi realizado no município de Seropédica, RJ, em casa de vegetação localizada no Departamento de Solos da Universidade Federal Rural do Rio de Janeiro (UFRRJ), no período de 09/11/2011 a 30/11/2011.

Foi utilizado material de solo proveniente de um Planossolo Háplico (Embrapa, 2006), textura arenosa, coletado da camada superficial $(0-20 \mathrm{~cm})$, localizado na antiga rodovia RJ-SP, $\mathrm{km} \mathrm{47,} \mathrm{UFRRJ,} \mathrm{nas}$ coordenadas geográficas $22^{\circ} 45^{\prime}$ de latitude sul e $43^{\circ} 41^{\prime}$ de longitude oeste. Após a coleta, o solo foi seco, destorroado, peneirado (malha $2 \mathrm{~mm}$ ), homogeneizado e submetido à análise química, que foi realizada no Laboratório de Fertilidade do Solo do Departamento de Solos/UFRRJ, de acordo com Embrapa (1997), apresentando os seguintes resultados: 0,$016 ; 1,2 ; 0,3 ; 2,5 ; 0,5 ; 1,59 ;$ e $4,09 \mathrm{cmol}_{\mathrm{c}} \mathrm{dm}^{-3}$, 
respectivamente para teores de $\mathrm{Na}, \mathrm{Ca}, \mathrm{Mg}, \mathrm{H}+\mathrm{Al}$, $\mathrm{Al}$, valor $\mathrm{S}$ e valor $\mathrm{T} ; \mathrm{pH}\left(\mathrm{H}_{2} \mathrm{O}\right)=5,5$; carbono orgânico $=1,02 \mathrm{~g} \mathrm{~kg}^{-1} ; 3$ e $30 \mathrm{mg} \mathrm{dm}^{-3}$ de $\mathrm{Pe} \mathrm{K}$, respectivamente.

$\mathrm{O}$ solo foi submetido à calagem pelo método da curva de neutralização, a fim de elevar o $\mathrm{pH}$ a 6,5 , segundo incubação proposta por Stafanato (2009), objetivando maximizar a ação da enzima urease e consequentemente as perdas de $\mathrm{N}-\mathrm{NH}_{3}$ por volatilização. Posteriormente, esse foi alocado até a superfície de bandejas plásticas com $0,1 \mathrm{~m}^{2}$ de área e $10 \mathrm{~cm}$ de profundidade, as quais constituíram as unidades experimentais.

Foi adotado o delineamento inteiramente casualizado com 10 tratamentos (Quadro 1) e três repetições. O processo consistiu na compactação de ureia com as fontes de $\mathrm{S}$ e bentonita.

Adicionou-se uma lâmina de água com auxílio de uma proveta graduada equivalente a $18 \mathrm{~mm}$, para que o solo contido nas bandejas alcançasse $70 \%$ da sua capacidade de campo, estimulando assim a produção de urease pelo solo. Posteriormente, os fertilizantes nitrogenados foram aplicados manualmente de maneira uniforme na superfície do solo contido nas bandejas, em dose equivalente a $200 \mathrm{~kg}$ ha ${ }^{1}$ de N, e, imediatamente após, as câmaras coletoras de $\mathrm{N}-\mathrm{NH}_{3}$ (Figura 1) foram colocadas na superfície desse solo. Utilizaram-se duas câmaras por bandeja, que foram movimentadas diariamente após cada coleta de forma a percorrer toda a área da bandeja. Tal procedimento objetivou reduzir as variações comumente observadas em ensaios de determinação de $\mathrm{N}-\mathrm{NH}_{3}$ volatilizado do solo.

Em razão de pesquisas realizadas no Brasil apresentarem que, para a maioria das situações, a máxima eficiência do inibidor da urease NBPT varia de três a sete dias, e que após esse período o NBPT perde gradativamente o seu efeito inibitório (Cantarella, 2007), optou-se em conduzir as coletas de volatilização por um período maior, com o intuito de observar melhor a dinâmica de perdas de $\mathrm{N}$ provenientes da ureia pastilhada com enxofre e bentonita.

Assim, as coletas do volatilizado foram realizadas até $021^{\circ}$ dia após a adubação, de maneira intercalada, da seguinte forma: em intervalos de $24 \mathrm{~h}$ até o sexto dia; e, após, as determinações foram realizadas no oitavo, $10^{\circ}, 14^{\circ}, 18^{\circ}$ e $21^{\circ}$ dias após a aplicação dos fertilizantes. Isso permitiu avaliar a dinâmica das perdas de amônia ao longo do tempo. Durante todo o período experimental, a umidade do solo foi mantida entre 50 a $70 \%$ de retenção de água no solo. A análise da amônia volatilizada foi realizada segundo Araújo et al. (2009).

A temperatura máxima média e a umidade média no interior da casa de vegetação (Figura 2 ) foram de aproximadamente $33,1^{\circ} \mathrm{C}$ e $70,8 \%$, respectivamente, clima esse favorável à hidrólise da ureia e às perdas por volatilização da amônia, reflexo da forte corrente de ar provocada pelos exaustores e pelas altas temperaturas. $\mathrm{O}$ solo utilizado neste trabalho, por ser de textura arenosa e assim apresentar baixa capacidade de retenção de água aliada a uma maior taxa de evaporação, influenciou também no fluxo de água e, consequentemente, de $\mathrm{N}-\mathrm{NH}_{3}$ para a atmosfera. Estudos têm demonstrado que a atividade da urease aumenta com a elevação da temperatura de 10 para $40{ }^{\circ} \mathrm{C}$ (Lai \& Tabatabai, 1992) e que a hidrólise da ureia é potencializada com a manutenção do conteúdo de água no solo próximo da sua capacidade de campo (Antil et al., 1993). No primeiro dia após a adubação, houve um pico na temperatura máxima no interior da casa de vegetação, que atingiu $50{ }^{\circ} \mathrm{C}$, em razão de uma interrupção do fornecimento de energia elétrica, uma vez que a casa de vegetação em questão é dependente de eletricidade para seu funcionamento. Esse fator isolado provavelmente influenciou nas perdas de amônia e consequentemente na sua dinâmica para alguns tratamentos avaliados.

\section{Quadro 1. Tratamentos testados no experimento}

\begin{tabular}{|c|c|c|c|}
\hline Fertilizante & Tecnologia & Composição & Proporção N:S:bentonita \\
\hline & & & $\%$ \\
\hline Ureia $_{\mathrm{SH}}$ & Compactada & Ureia/ $\left(\mathrm{NH}_{4}\right)_{2} \mathrm{SO}_{4}$ & $37,8: 7,2: 0,0$ \\
\hline Ureia $_{\text {So }}$ & Compactada & Ureia/S $\mathrm{S}_{\text {elementar }}$ & $41,6: 7,2: 0,0$ \\
\hline Ureia $_{\mathrm{SHoB}}$ & Compactada & Ureia/ $\left(\mathrm{NH}_{4}\right)_{2} \mathrm{SO}_{4} / \mathrm{S}_{\text {elementar }} /$ bentonita & $39,51: 7,2: 0,38$ \\
\hline Ureia $_{\mathrm{SoB}}$ & Compactada & Ureia/S $\mathrm{S}_{\text {elementar }} /$ bentonita & $41,25: 7,2: 0,76$ \\
\hline Ureia pastilhada & Pastilhada & Ureia & $45: 0,0: 0,0$ \\
\hline Ureia granulada $^{(1)}$ & Granulada & Ureia & $45: 0,0: 0,0$ \\
\hline Ureia + $\mathrm{NBPT}^{(1)}$ & Revestida & Ureia/NBPT & $45: 0,0: 0,0$ \\
\hline Ureia $_{\mathrm{PSo}}^{(1)}$ & Pastilhada & Ureia/ $\mathrm{S}_{\text {elementar }}$ & $42: 9,2: 0,0$ \\
\hline Ureia $_{\mathrm{RSo}}{ }^{(1)}$ & Revestida & Ureia/ $\mathrm{S}_{\text {elementar }}$ & $43,4: 7,9: 0,0$ \\
\hline Sulfato de amônio ${ }^{(1)}$ & Cristal & $\left(\mathrm{NH}_{4}\right)_{2} \mathrm{SO}_{4}$ & $21: 24: 0,0$ \\
\hline
\end{tabular}

(1) Fertilizantes comerciais. 


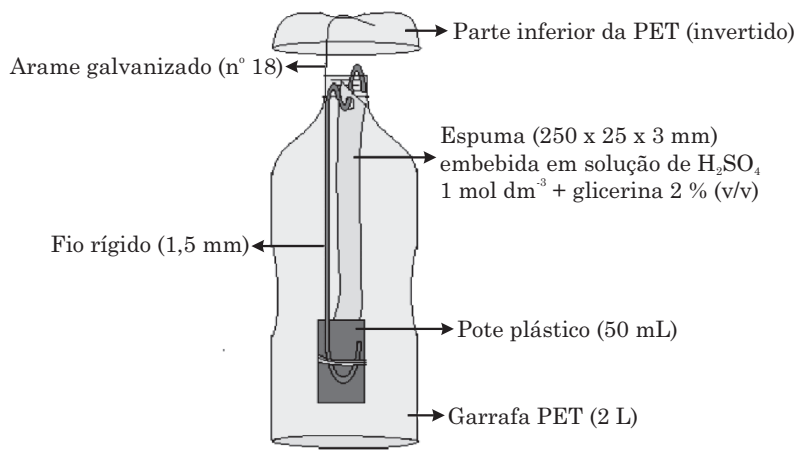

Figura 1. Esquema do sistema coletor de $\mathrm{N}-\mathrm{NH}_{3}$ semiaberto livre estático "Sale”. Fonte: Araújo et al. (2009).

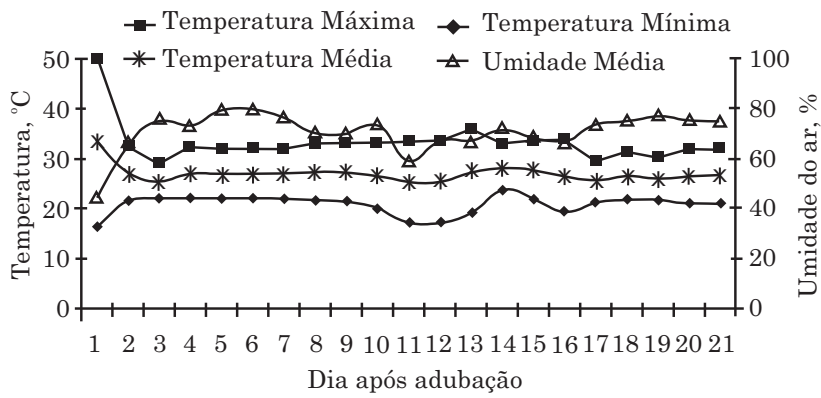

Figura 2. Temperatura e umidade relativa no interior da casa de vegetação referentes ao período de avaliação das perdas por volatilização da amônia.

A análise dos dados foi realizada utilizando-se o programa SAEG 9.1. Os dados foram submetidos às pressuposições de normalidade e homogeneidade dos erros, utilizando respectivamente os testes de Lilliefors e Bartlet. Usaram-se o Teste $\mathrm{F}$ para as variâncias e o de Scott-Knott a $5 \%$, para comparação de médias.

\section{RESULTADOS E DISCUSSÃO}

As perdas totais por volatilização de $\mathrm{N}-\mathrm{NH}_{3}$ mais consideráveis foram observadas nos tratamentos ureiaRSo com perdas de 45,1\% $\left(90,2 \mathrm{~kg} \mathrm{ha}^{-1} \mathrm{de} \mathrm{N}\right)$, ureia granulada com perdas de 44,9\% $\left(89,7 \mathrm{~kg} \mathrm{ha}^{-1}\right.$ de N), ureia pura pastilhada com perdas de $42,9 \%$ $\left(85,7 \mathrm{~kg} \mathrm{ha}^{-1}\right.$ de N) e ureia + NBPT com perdas de $41,4 \%\left(82,8 \mathrm{~kg} \mathrm{ha}^{-1}\right.$ de N) (Figura 3). As perdas de N oriundas da ureia pura pastilhada foram semelhantes às observadas por Stafanato et al. (2013), uma vez que esses verificaram não haver diferença da forma do fertilizante em minimizar as perdas de $\mathrm{N}$ por volatilização de amônia.

As maiores perdas de $\mathrm{N}-\mathrm{NH}_{3}$ por volatilização ocasionadas pelo tratamento ureia + NBPT podem ser explicadas pela alta temperatura $\left(50{ }^{\circ} \mathrm{C}\right)$ na casa de vegetação no primeiro dia após a adubação, o que ocasionou para esse dia em uma perda de $44 \%$ $\left(36,4 \mathrm{~kg} \mathrm{ha}^{-1}\right.$ de $\left.\mathrm{N}\right)$ do total de $\mathrm{N}$ perdido por volatilização de amônia $\left(82,8 \mathrm{~kg} \mathrm{ha}^{-1} \mathrm{de} \mathrm{N}\right)$. Segundo Rawluck et al. (2001), o NBPT tende a ser menos eficiente em altas temperaturas, em razão da ocorrência de maior atividade da urease, ocasionando maior dissolução dos grânulos e consequentemente maior evaporação da solução do solo. Além disso, em temperaturas elevadas, a taxa de hidrólise da ureia pode ultrapassar a taxa de conversão de NBPT para NBPTO. Isso ocorre porque o NBPT não é o inibidor direto da urease, pois, uma vez aplicado ao solo, o NBPT tem que ser convertido ao seu análogo de oxigênio - NBPTO, que é o verdadeiro inibidor da urease (Christianson et al., 1990). Estudos demonstraram que a eficiência do NBPT decresce com a elevação da temperatura de 10 para $40{ }^{\circ} \mathrm{C}$ (Bremner $\&$ Chai, 1986). A atividade da urease também se intensifica com a elevação da temperatura de 10 para $40{ }^{\circ} \mathrm{C}$, diminuindo dessa maneira a eficiência desse composto (Lai \& Tabatabai, 1992).

A incorporação de fontes de $\mathrm{S}$ e de bentonita na ureia compactada reduziu as perdas de $\mathrm{N}-\mathrm{NH}_{3}$ por volatilização em torno de $21 \%$, quando comparadas com as perdas ocasionadas pela ureia granulada. $\mathrm{O}$ tratamento que recebeu a ureia compactada com $\mathrm{S}$ elementar e bentonita (ureiaSoB) com perdas de $80 \mathrm{~kg} \mathrm{ha}^{-1}$ de $\mathrm{N}-\mathrm{NH}_{3}$ diferiu significativamente dos demais, resultando na maior perda de amônia por volatilização entre os compactados de ureia, S e bentonita. Quando comparada com as perdas da ureia $\left(90 \mathrm{~kg} \mathrm{ha}^{-1} \mathrm{~N}-\mathrm{NH}_{3}\right.$ ), esse tratamento a reduziu em aproximadamente $11 \%$ (Figura 3 ).

Os produtos oriundos da compactação de ureia com S elementar (ureiaSo), ureia com sulfato de amônio, Selementar e bentonita (ureiaSHoB) com perdas em torno de 68 e $71,7 \mathrm{~kg} \mathrm{ha}^{-1}$ de $\mathrm{N}-\mathrm{NH}_{3}$ respectivamente, não diferiram das perdas de amônia apenas do fertilizante comercial ureiaPSo (ureia pastilhada com enxofre elementar), que resultou em perdas em torno $70 \mathrm{~kg} \mathrm{ha}^{-1} \mathrm{de} \mathrm{N}-\mathrm{NH}_{3}$. Esse efeito, em média, ocasionou redução nas perdas de amônia por volatilização em torno de $23 \%$, enquanto o produto comercial minimizou as perdas de amônia em torno de $22 \%$, quando comparadas com as provocadas pelo uso de ureia granulada comercial (Figura 3).

Entre os tipos de ureia compactada com fontes de $\mathrm{S}$ e bentonita, o que resultou na menor perda de $\mathrm{N}$ $\mathrm{NH}_{3}$ por volatilização foi proveniente de compactação de ureia com sulfato de amônio (ureiaSH). Esse diferiu significativamente dos demais tratamentos, resultando em perdas em torno de $32 \%$ da dose de $\mathrm{N}$ aplicada, equivalendo a $64 \mathrm{~kg} \mathrm{ha}^{-1} \mathrm{de} \mathrm{N}-\mathrm{NH}_{3}$. Quando comparada com as perdas de amônia ocasionadas pela ureia granulada, a ureiaSH conseguiu reduzi-las em torno de 29 \% (Figura 3). A dinâmica de perdas do sulfato de amônio já foi estudada quanto à quantificação de perdas de $\mathrm{N}-\mathrm{NH}_{3}$ por volatilização em diferentes condições edafoclimáticas, e os 
resultados observados foram semelhantes aos encontrados neste estudo (Pereira et al., 2009). A bentonita é uma argila expansiva que possui excelentes propriedades, como: alta capacidade de inchamento, podendo atingir 20 vezes seu volume inicial quando em contato com a água; e elevada área superficial e um elevado poder de troca de cátions, que diz respeito à sua configuração estrutural entre camadas (Smith et al., 1990). Essa alta capacidade de troca de cátions aliada às suas cargas negativas em sua superfície pode então conferir às bentonitas compactadas com a ureia uma capacidade de adsorver cátions como o amônio. Dessa forma, verificou-se que a incorporação isolada de bentonita ou em conjunto com fontes de enxofre na ureia compactada (ureiaB e ureiaSHoB) demonstrou ser alternativa viável para minimizar as perdas de $\mathrm{N}-\mathrm{NH}_{3}$ por volatilização.

A intensidade máxima de perdas de $\mathrm{N}-\mathrm{NH}_{3}$ por volatilização deu-se preferencialmente nas primeiras 48 h, após a aplicação dos fertilizantes (Figura 4). Foram apresentadas as perdas referentes aos 10 primeiros dias, uma vez que após esse período os fertilizantes avaliados praticamente não apresentaram grandes variações da dinâmica de perdas de amônia por volatilização. A ureia logo que aplicada ao solo normalmente é hidrolisada em dois ou três dias, sendo as perdas por volatilização de $\mathrm{N}-\mathrm{NH}_{3}$ mais

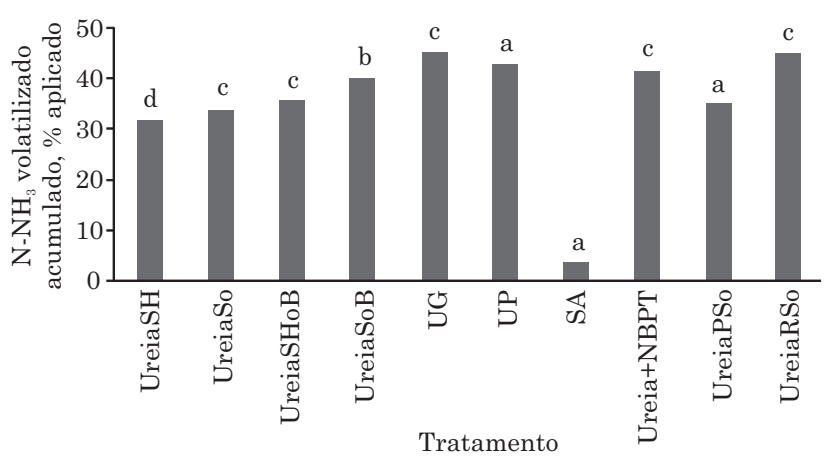

Figura 3. Perdas acumuladas por volatilização de $\mathrm{N}-\mathrm{NH}_{3}$ provenientes dos fertilizantes compactados de ureia com fontes de enxofre e bentonita após 21 dias de avaliação. Médias seguidas de letras distintas diferem entre si pelo teste de ScottKnott a $5 \%$.

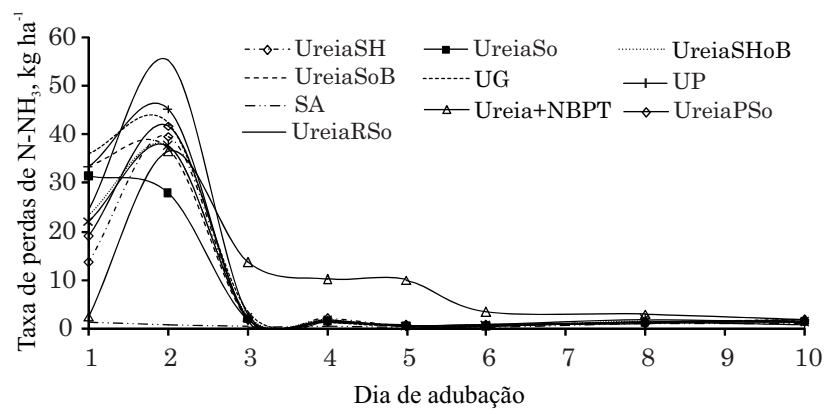

Figura 4. Taxa diária de perdas de $\mathrm{N}-\mathrm{NH}_{3}$ dos diferentes fertilizantes nitrogenados ao longo do tempo. significativas ocorrendo nesse período (Da Ros et al., 2005). Entretanto, em virtude de ter ocorrido um pico na temperatura no interior da casa de vegetação $50{ }^{\circ} \mathrm{C}$, no primeiro dia após a adubação, como apresentado na figura 2 , o que provavelmente influenciou de forma negativa na dinâmica de perdas de amônia, pode ter feito com que a ureia compactada com diferentes fontes de enxofre e bentonita não conseguisse expressar maior eficiência, assim também para os produtos comerciais ureiaPSo (ureia pastilhada com S elementar), ureiaRSo (ureia perolada revestida com $\mathrm{S}$ elementar) e principalmente a ureia contendo inibidor da urease (ureia + NBPT). Contudo, o pico de perdas oriundos da ureia compactada com $\mathrm{S}$ e bentonita foram inferiores aos picos ocasionados pela ureia granulada comercial, ureiaPSo e ureiaRSo.

Um resultado interessante observado foi a dinâmica da ureia contendo inibidor da urease (ureia + NBPT) em relação às perdas de $\mathrm{N}-\mathrm{NH}_{3}$. Verifica-se, na figura 4, que, esse produto resultou em pico de perda no segundo dia após a adubação, e que, a partir do terceiro dia ao $10^{\circ}$, esse tratamento resultou em maiores perdas diárias de $\mathrm{N}-\mathrm{NH}_{3}$ por volatilização do que em relação aos demais. Bremner \& Chai (1986) observaram diminuição da eficiência do NBPT quando a temperatura foi elevada de 10 para $40^{\circ} \mathrm{C}$, e que esse efeito da temperatura foi maior aos 14 dias após a adubação do que aos três e sete dias, após a aplicação do produto. Entretanto, de forma contrária, para esse ensaio, o pico de perda observado na ureia + NBPT ocorreu logo após esse ser exposto a uma temperatura de $50{ }^{\circ} \mathrm{C}$. Assim, de acordo com Watson et al. (1994), em condições adversas e quando o inibidor (NBPT) é submetido a um longo período de exposição, são necessárias maiores concentrações de NBPTO para que então esse possa alcançar níveis de inibição que seriam obtidos em condições favoráveis.

As perdas de $\mathrm{N}-\mathrm{NH}_{3}$ por volatilização da ureia com sulfato de amônio na forma compactada (ureiaSH) de 29 \% menor, quando comparadas com a ureia granulada (Figura 3), ocorreram em virtude da presença de fertilizantes acidificantes como o sulfato de amônio, que minimiza as perdas de $\mathrm{N}-\mathrm{NH}_{3}$. Vitti et al. (2002) verificaram que a mistura de ureia com o sulfato de amônio aplicada ao solo resultou em menores perdas de amônia por volatilização. Estes autores atribuíram a essa menor perda ao efeito de controle de elevação do $\mathrm{pH}$ e à redução na quantidade de $\mathrm{N}$ amídico proporcionado pela mistura, pois as perdas por volatilização tendem a aumentar com a elevação da concentração ou da dose de ureia.

O S elementar não é a forma prontamente disponível para as plantas, necessitando ser oxidado à forma de sulfato no solo, sendo essa oxidação realizada por bactérias do gênero Thiobacillus, cuja reação de oxidação acidifica o solo (Alvarez V. et al., 2007). Contudo, não foi observado tal benefício na 
ureia comercial revestida com $\mathrm{S}$ elementar (ureiaRSo), uma vez que a forma como esse $\mathrm{S}$ elementar é incorporado aos fertilizantes pode influenciar sua velocidade de oxidação a sulfato no solo, ao passo que a incorporação de S elementar na ureia compactada (ureiaSo) evidenciou-se efetiva em reduzir as perdas de $\mathrm{N}-\mathrm{NH}_{3}$. Isso ocorreu provavelmente porque o $\mathrm{S}$ do revestimento pode formar partículas maiores no solo do que quando dispersos nos grânulos dos fertilizantes, uma vez que partículas finas agregadas entre si têm menor área superficial do que quando dispersas e misturadas ao solo, facilitando assim a ação das bactérias oxidativas (Horowitz, 2003; Horowitz \& Meurer, 2006).

Contudo, quando o S elementar é incorporado no mesmo grânulo com bentonita, a taxa de oxidação desse elemento é geralmente menor do que em relação ao $\mathrm{S}$ elementar na forma de pó (Karamanos \& Janzen, 1991). Essa oxidação mais lenta tem sido atribuída à inadequada dispersão das partículas de S elementar, após aplicação do produto ao solo (Janzen, 1990).

\section{CONCLUSÕES}

1. As perdas por volatilização de $\mathrm{N}-\mathrm{NH}_{3}$ entre os fertilizantes avaliados, em ordem crescente, foram: sulfato de amônio $<$ ureiaSH $<$ ureiaSo $=$ ureiaPSo $=$ ureiaSHoB $<$ ureiaSoB $<$ ureia $+\mathrm{NBPT}=$ ureia pastilhada $=$ ureia granulada $=$ ureiaRSo.

2. A compactação de sulfato de amônio e ureia demonstrou ser eficiente contra as perdas de N-NH por volatilização, reduzindo em até 29 \% a volatilização quando comparada com a ureia granulada comercial.

3. A compactação de ureia com bentonita em conjunto com fontes de enxofre demonstraram ser alternativas viáveis para aumentar a eficiência do $\mathrm{N}$-ureia.

\section{AGRADECIMENTOS}

À Petrobrás, pelo financiamento do projeto de pesquisa; à Capes, pela concessão da bolsa de estudo; e ao Curso de Pós-Graduação em Ciência do Solo da Universidade Federal Rural do Rio de Janeiro.

\section{LITERATURA CITADA}

ALVAREZ V., V.H.; ROSCOE, R.; KURIHARA, C.H. \& PEREIRA, N.F. Enxofre. In: NOVAIS, R.F.; ALVAREZ V., V.H.; BARROS, N.F.; FONTES, R.L.F.; CANTARUTTI, R.B. \& NEVES, J.C.L., eds. Fertilidade do solo. Viçosa, MG, Sociedade Brasileira de Ciência do Solo, 2007. p.595-646.
ANTIL, R.S.; GUPTA, A.P. \& NARWAL, R.P. Effect of substrate concentration, soils tures and organic amendments on urease activity of soil containing variable amnoicuknetls. Arid Soil Res. Rehab., 7:381387, 1993.

ARAÚJO, E.S.; MARSOLA, T.; MIYAZAWA, M.; SOARES, L.H.B.; URQUIAGA, S.; BODDEY, R.M. \& ALVES, B.J.R. Calibração de câmara semiaberta estática para quantificação de amônia volatilizada do solo. Pesq. Agropec. Bras., 44:769-776, 2009.

BREMNER, J.M. \& CHAI, H.S. Evaluation of N-butyl phosphoric triamide for retardation or urea hidrolysis in soil. Commun. Soil Sci. Plant Anal., 17:337-351, 1986.

CANTARELLA, H. Nitrogênio. In: NOVAIS, R.F.; ALVAREZ V., V.H.; BARROS, N.F.; FONTES, R.L.F.; CANTARUTTI, R.B. \& NEVES, J.C.L., eds. Fertilidade do solo. Viçosa, MG, Sociedade Brasileira de Ciência do Solo, 2007. p.375-470.

CHRISTIANSON, C.B.; BYRNES, B.H. \& CARMONA, G. A comparison of the sulfur and oxygen analogs of phosphoric triamide urease inhibitors in reducing urea hydrolysis and ammonia volatilization. Fert. Res., 26:2127, 1990 .

DA ROS, C.O.; AITA, C. \& GIACOMINI, S.J. Volatilização de amônia com aplicação de ureia na superfície do solo, no sistema plantio direto. Ci. Rural, 35:799-805, 2005.

EMPRESA BRASILEIRA DE PESQUISA AGROPECUÁRIA - EMBRAPA. Centro Nacional de Pesquisa de Solos. Sistema brasileiro de classificação de solos. 2.ed. Rio de Janeiro, 2006. 306p.

EMPRESA BRASILEIRA DE PESQUISA AGROPECUÁRIA - EMBRAPA. Centro Nacional de Pesquisa de Solos. Manual de métodos de análise de solo. Rio de Janeiro, 1997. $212 \mathrm{p}$

FACRE, W.R. Três formas de fertilizantes nitrogenados e o futuro. Inf. Agron., 120:5-6, 2007.

HOROWITZ, N. Oxidação e eficiência agronômica do enxofre elementar em solos do Brasil. Porto Alegre, Universidade Federal do Rio Grande do Sul, 2003. 119p. (Tese de Doutorado)

HOROWITZ, N. \& MEURER, E.J. Oxidação do enxofre elementar em solos tropicais. Ci. Rural, 36:822-828, 2006.

JANZEN, H.H. Elemental sulfur oxidation as influenced by plant growth and degree of dispersion within soil. Can. J. Soil Sci., 70:499-502, 1990.

KARAMANOS, R.E. \& JANZEN, H.H. Crop response to elemental sulfur fertilizers in Central Alberta. Can. J. Soil Sci., 71:213-225, 1991.

KHALIL, M.I.; SCHMIDHALTER, U. \& GUTSER, R. $\mathrm{N}_{2} \mathrm{O}$, $\mathrm{NH}_{3}$ and $\mathrm{NO}_{\mathrm{x}}$ emissions as a function of urea granule size and soil type under aerobic conditions. Water Air Soil Pollut., 175:127-148, 2006.

KIEHL, J.C. Distribuição e retenção da amônia no solo após a aplicação de ureia. R. Bras. Ci. Solo, 13:75-80, 1989. 
LAI, C.M. \& TABATABAI, M.A. Kinetic parameters of immobilized urease. Soil Biol. Biochem., 24:225-228, 1992.

LARA CABEZAS, W.A.R.; TRIVELIN, P.C.O. \& BOARETTO, A.E. Efeito do tamanho de grânulo e relação N/S da ureia aplicada em superfície na volatilização de amônia sob diferentes umidades iniciais do solo. R. Bras. Ci. Solo, 16:409-413, 1992.

PEREIRA, H.S.; LEAO, A.F.; VERGINASSI, A. \& CARNEIRO, M.A.C. Ammonia volatilization of urea in the out-of-season corn. R. Bras. Ci. Solo, 33:1685-1694, 2009 .

RAWLUCK, C.D.L.; GRANT, C.A. \& RACZ, G.J. Ammonia volatilization from soils fertilized with ureia and varying rates of urease inhibitor NBPT. Can. J. Soil Sci., 81:239$246,2001$.

REYNOLDS, C.M. \& WOLF, D.C. Effects of soil moisture and air relative humidity on ammonia volatilization from surfaces-applied urea. Soil Sci., 143:144-152, 1987.

RODRIGUES, M.B. \& KIEHL, J.C. Distribuição e nitrificação da amônia proveniente da ureia aplicada ao solo. R. Bras. Ci. Solo, 16:403-408, 1992.
SMITH, J.A.; JAFF, P.R. \& CHLOU, C.T. Effect of tem quaternary ammonium cations on tetrachloromethane sorption to clay from water. Environ. Sci. \& Technol., 24:1167-1172, 1990.

STAFANATO, J.B. Aplicação de misturas granuladas NK e NS em cultivar de arroz (Oryza sativa). Seropédica, Universidade Federal Rural do Rio de Janeiro, 2009. 67p. (Dissertação de Mestrado)

STAFANATO, J.B.; GOULART, R.S.; ZONTA, E.; LIMA, E.; MAZUR, N.; PEREIRA, C.G. \& SOUZA, H.N. Volatilização de amônia oriunda de ureia pastilhada com micronutrientes em ambiente controlado. R. Bras. Ci. Solo, 37:726-732, 2013.

VITTI, G.C.; TAVARES, J.E.; LUZ, P.H.C.; FAVARIN, J.L. \& COSTA, M.C.G. Influência da mistura de sulfato de amônio com ureia sobre a volatilização de nitrogênio amoniacal. R. Bras. Ci. Solo, 26:663-671, 2002.

WATSON, C.J.; MILLER, H.; POLAND, P.; KILPATRICK, D.J.; ALLEN, M.B.D.; GARRET, M.K. \& CHRISTIANSON, C.B. Soil properties and the ability of the urease inhibitor $\mathrm{N}$-(n-butyl) thiophosporic triamide (nBTPT) to reduce ammonia volatilization from surface-applied urea. Soil Biol. Biochem., 26:1165-1171, 1994. 